\title{
Some Facts about Cancer in Karbala Province of Iraq, 2012-2020
}

\section{Ahmed Mjali, Bushra Najeh Hasan Al Baroodi}

Department of Hematology /Oncology, Al- Hussein Medical City, Karbala, Iraq.

\author{
Asian Pac J Cancer Care, 5 (2), 67-69
}

In 2018, more than 18 million new cases of cancer occurred around the world [1]. In Iraq there are over 31,500 cases of cancer between $2017 \& 2018$ making it one of the country's leading causes of death, contributing to an estimated $11 \%$ of total deaths [2]. Some experts argue that the leading cause behind cancer in Iraq is radioactive and environmental pollution due to the contamination of water, air and soil with carcinogens such as petroleum compounds [3-4]. Here we investigated cancer distribution in Al-Hussein cancer center in Karbala province of Iraq from 2012 to 2020.This center was established in November 2011 with oncology \& hematology wards while health authorities in Karbala are planning for establishing radiotherapy department in future. This centre covers not only Karbala population but other patients from middle Euphrates region in Iraq are referred to this center for solid\& hematological malignancy treatment [5]. There were 7468 cases were registered, male were 3117 patients (41.74\%) and female were 4351 patients $(58.26 \%)$, with (male to female ratio $=0.71: 1$ ). Female predominant may be explained by that our center is a referral center and many certain cancer like breast cancer refer to this center making the number of female more than male. People above 40 years old represent the majority of patients, presenting about $72.90 \%$ of cases. While those $\leq 20$ years presenting about $11.40 \%$ (Table 1).

In general regardless of sex, breast cancer was the most common cancer registered in our center presenting about $(24.49 \%)$, followed by lymphoma $(8.90 \%)$, urinary bladder $(7.53 \%)$, lung $(7.36 \%)$, leukemia $(6.93 \%)$, colorectal $(6.42 \%)$, brain $(5.16 \%)$, ovarian $(3.02 \%)$, soft tissue sarcoma $(2.97 \%)$ and prostate $(2.97 \%)$ as shown in (Figure 1).

Top ten cancer type in males were urinary bladder (13.21\%), lung (11.22\%), lymphoma (10.60\%), leukemia $(9.23 \%)$, colorectal $(8.40 \%)$, prostate $(7.12 \%)$, head and neck $(4.30 \%)$, soft tissue $(3.91 \%)$, pancreas $(3.68 \%)$ and brain $(3.50 \%)$ as shown in (Figure 2 ) and (Table 2).

While the top ten cancer in females were breast
Submission Date: 02/17/2020 Acceptance Date: 05/02/2020

Table 1. Incidence Rate of Cancer According to Patients' Age

\begin{tabular}{lcc}
\hline & \multicolumn{2}{c}{ Gender } \\
& Male n (\%) & Female n (\%) \\
\hline $0-10$ & $253(8.12)$ & $277(6.37)$ \\
$11-20$ & $164(5.26)$ & $157(3.61)$ \\
$21-30$ & $168(5.39)$ & $246(5.65)$ \\
$31-40$ & $238(7.63)$ & $521(11.97)$ \\
$41-50$ & $425(13.63)$ & $1060(24.36)$ \\
$51-60$ & $575(18.45)$ & $956(21.97)$ \\
$61-70$ & $772(24.77)$ & $799(18.36)$ \\
$71-80$ & $430(13.80)$ & $269(6.18)$ \\
$81-90$ & $85(2.73)$ & $60(1.38)$ \\
$91-100$ & $7(0.22)$ & $6(0.15)$ \\
\hline
\end{tabular}

(41.50\%), lymphoma (7.70\%), leukemia (5.30\%), ovarian (5.20\%), colorectal (5\%), lung (4.60\%), uterine \& cervical $(4.30 \%)$, urinary bladder $(3.50 \%)$, thyroid cancer $(2.70 \%)$ and soft tissue sarcoma (2.30\%) as shown in (Figure 3) and (Table 2).

The number of cancer cases that registered in 2012 were 483 cases, while in 2019 more than 1200 cases were registered (Figure 4). Increase in cancer patients was steady increase not sharp increase this due to natural growing of population, increase awareness of disease and improving in diagnosis \& registration. Our study may help to provide basic information to investigate epidemiological cancer characteristics, to assess progress in recent years and to develop future cancer treatment strategies.

\section{Conflicts of interest}

There are no conflicts of interest. 


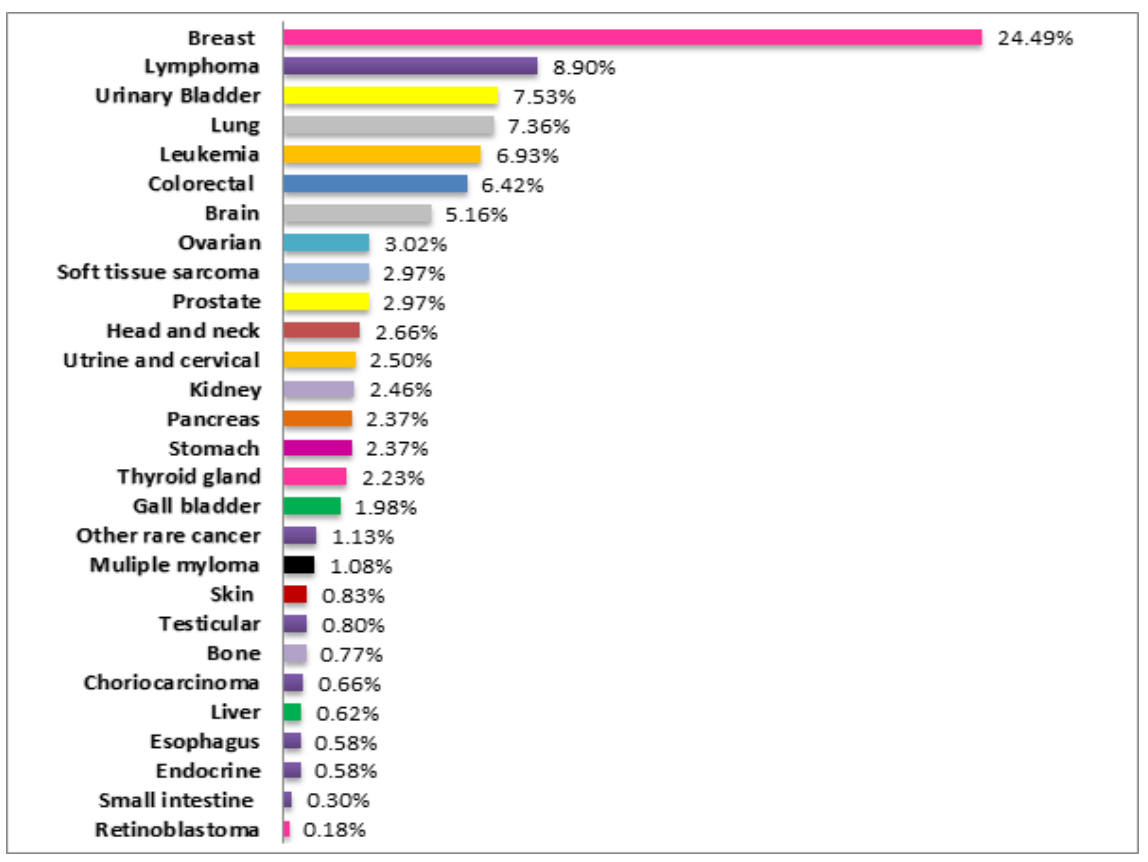

Figure 1. Incidence Rate of Cancer Types Regardless of Sex

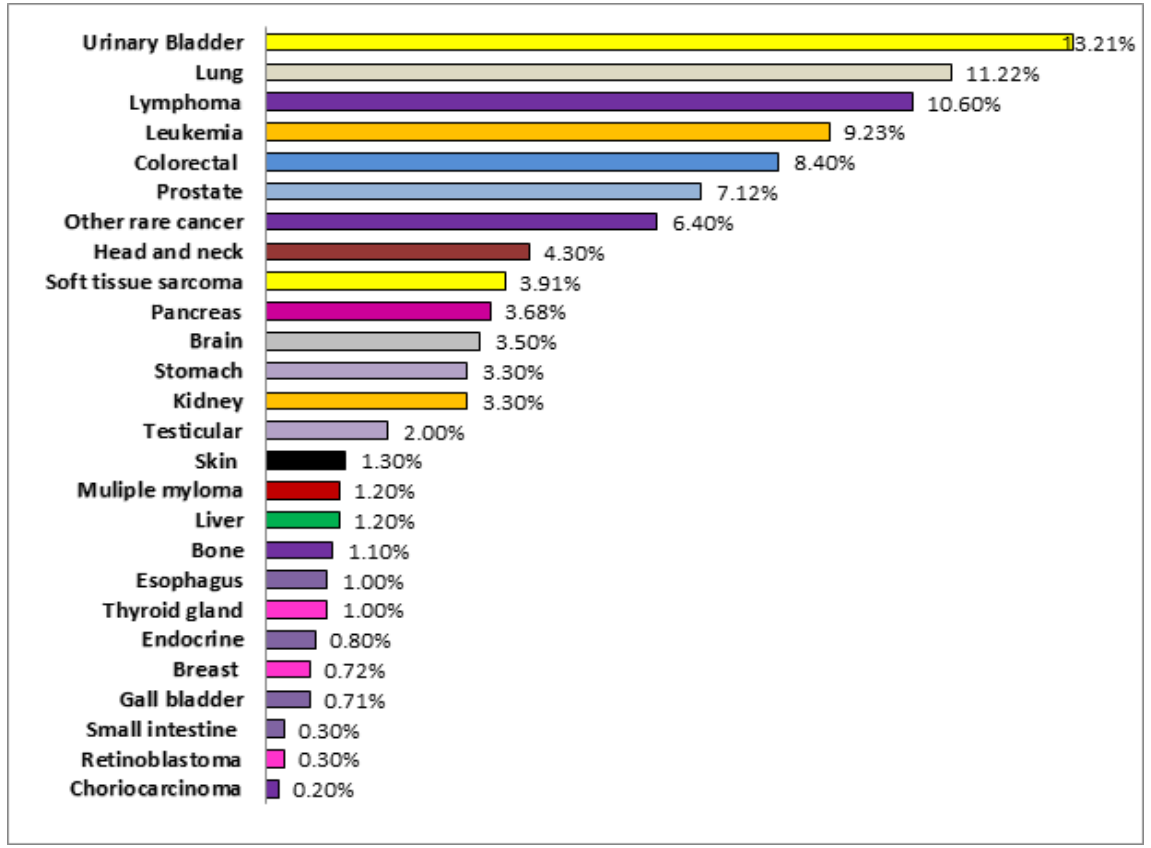

Figure 2. Incidence Rate of Cancer Types in Male

Table 2. Top Ten Cancer in Male and Female

\begin{tabular}{lcc}
\hline & Male $\mathrm{n}(\%)$ & Female $\mathrm{n}(\%)$ \\
\hline 1 & Urinary bladder 411 (13.21) & Breast 1806 (41.50) \\
2 & Lung 350 (11.22) & Lymphoma 335 (7.70) \\
3 & Lymphoma 330 (10.60) & Leukemia 231 (5.30) \\
4 & Leukemia 287 (9.23) & Ovarian 226 (5.20) \\
5 & Colorectal 218 (5) \\
6 & Prostate 222 (7.12) & Lung 200 (4.60) \\
7 & Head and neck 134(4.30) & Uterine \& cervical 187 (4.30) \\
8 & Soft tissue 122 (3.91) & Urinary bladder 152 (3.50) \\
9 & Pancreas 115(3.68) & Thyroid cancer 117 (2.70) \\
10 & Brain 110 (3.50) & Soft tissue sarcoma 100 (2.30) \\
11 & Other 774 (24.83) & Other 779 (17.90) \\
& Total 3117 (100) & Total 4351 (100) \\
\hline
\end{tabular}




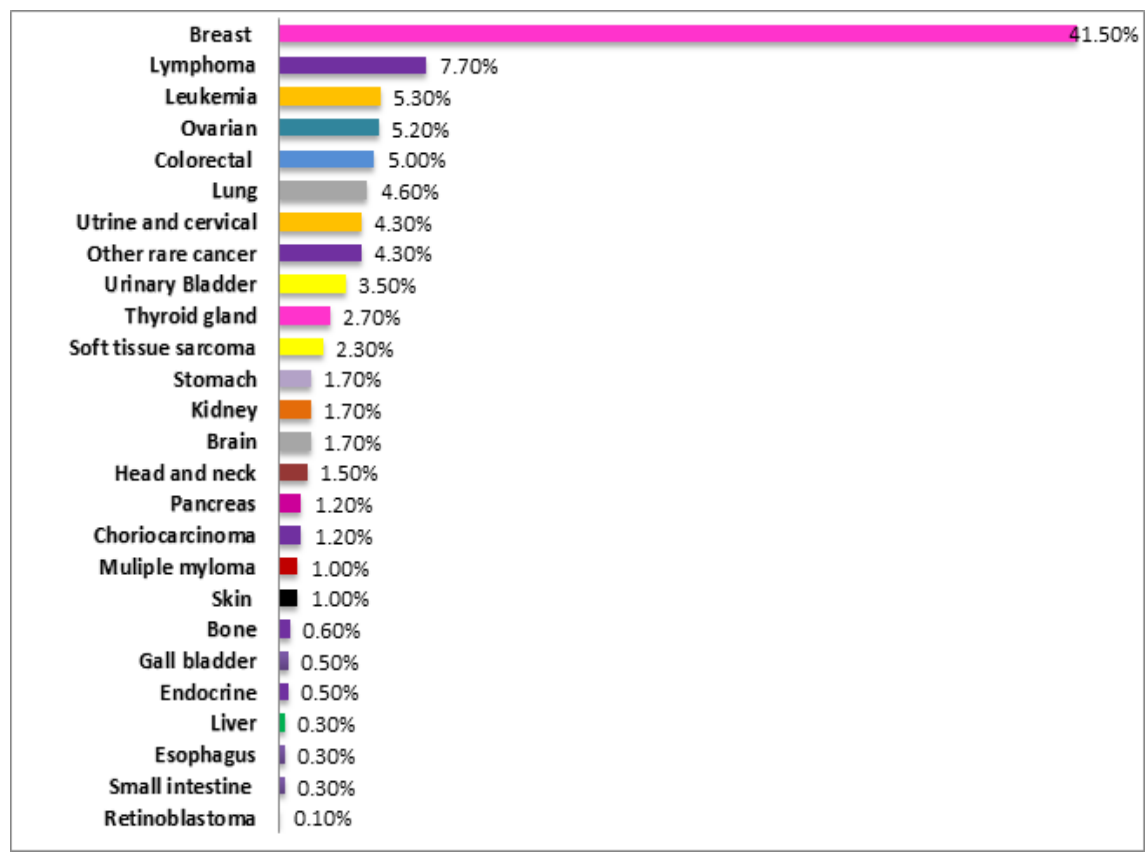

Figure 3. Incidence Rate of Cancer Types in Female

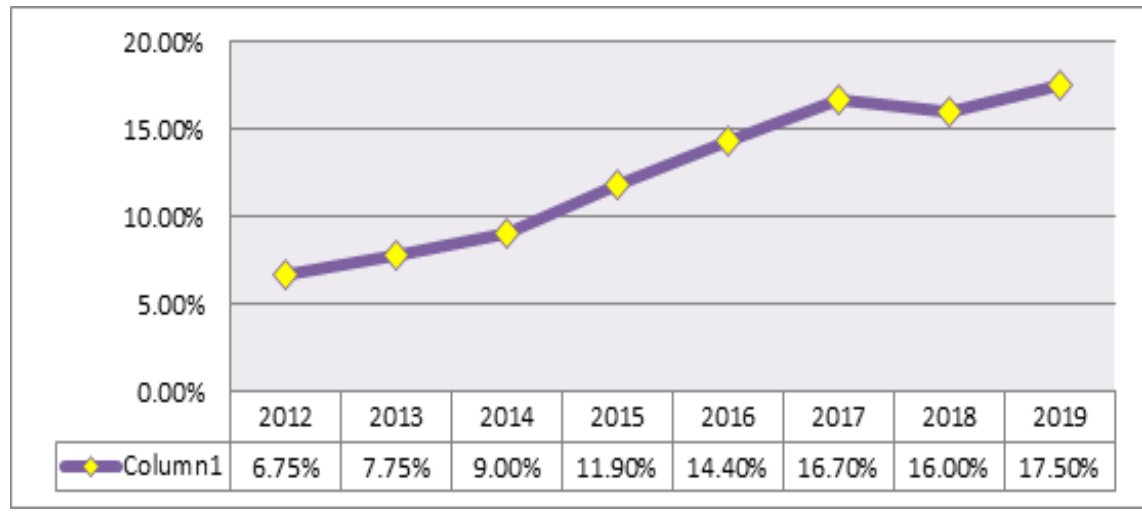

Figure 4. Percentage of Incidence Rate of Cancer Between 2012 to 2019

\section{References}

1. Bray F, Ferlay J, Soerjomataram I, Siegel RL, Torre LA, Jemal A. Global cancer statistics 2018: GLOBOCAN estimates of incidence and mortality worldwide for 36 cancers in 185 countries. CA Cancer J Clin. 2018 Nov;68(6):394-424.

2. WHO, Iraqi Cancer Data for 2017-2018 announcement [cited February 2020]. Available from:http://www.emro.who.int/ irq/iraq-news/cancer-data-for-20172018-announced-in-iraq. html .

3. Menkhi SA, Shanoon FH, Almayahi BA. Radiation pollution and cancer risks in Sulaimaniyah and Ninawa Cities, Iraq. Annu Res Rev Biol.2017 Oct 16:1-9.

4. Al-ShammariAM. Environmental pollutions associated to conflicts in Iraq and related health problems. Rev Environ Health. 2016 Jun 1;31(2):245-50.

5. Mjali A, Al-Shammari HH, Abbas NT, Azeez ZD, Abbas SK. Leukemia Epidemiology in Karbala province of Iraq. Asian Pac J Cancer Care. 2019;4(4):135-9.

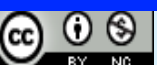

This work is licensed under a Creative Commons AttributionNon Commercial 4.0 International License. 